\title{
Curriculum and Community Enterprise for Restoration Sciences: The Expansion and Future of the Model
}

\author{
Lauren Birney ${ }^{1}$, Denise McNamara ${ }^{2}$, Catherine Sanders ${ }^{3}$, Hari Luintel ${ }^{3} \&$ Joshua Penman $^{3}$ \\ ${ }^{1}$ Pace University, USA \\ ${ }^{2}$ CUNY The College of Staten Island, USA \\ ${ }^{3}$ Smartstart Evaluation and Research, USA \\ Correspondence: Lauren Birney, Pace University, USA.
}

Received: September 9, 2018

Accepted: September 24, 2018

Online Published: November 7, 2018

doi:10.5430/irhe.v3n4p1

URL: https://doi.org/10.5430/irhe.v3n4p1

\section{National Science Foundation Award Number DRL 1440869}

Any findings, conclusions, or recommendations expressed in this material are those of the authors and other contributors and do not necessarily reflect the views of NSF.

\begin{abstract} CCERS implementation involves:

- 78 middle schools

- 127 teachers

- 110 scientist volunteers

- Over $5000 \mathrm{~K}-12$ students
\end{abstract}

The CCERS partnership includes collaborators from universities, foundations, education departments, community organizations, and cultural institutions to build a new curriculum. As reported in a study conducted by the Rand Corporation (2011), partnerships among districts, community-based organizations, government agencies, local funders, and others can strengthen learning programs. The curriculum merged project-based learning and Bybee's 5E model (Note 1) to teach core STEM-C concepts to urban middle school students through restoration science. CCERS has five interrelated and complementary programmatic pillars (see details in the next section). The CCERS curriculum encourages urban middle school students to explore and participate in project-based learning activities restoring the oyster population in and around New York Harbor. In Melaville, Berg and Blank's Community Based Learning (2001) there is a statement that says, "Education must connect subject matter with the places where students live and the issues that affect us all". Lessons engage students and teachers in long-term restoration ecology and environmental monitoring projects with STEM professionals and citizen scientists. In brief, partners have created curriculums for both in-school and out-of-school learning programs, an online platform for educators and students to collaborate, and exhibits with community partners to reinforce and extend both the educators' and their students' learning. Currently

In this report, we present summative findings from data collected via surveys among three cohorts of students whose teachers were trained by the project's curriculum and findings from interviews among project leaders to answer the following research questions:

1. Do the five programmatic pillars function independently and collectively as a system of interrelated STEM-C content delivery vehicles that also effectively change students' and educators' disposition towards STEM-C learning and environmental restoration and stewardship?

2. What comprises the "curriculum plus community enterprise" local model?

3. What are the mechanisms for creating sustainability and scalability of the model locally during and beyond its five-year implementation?

4. What core aspects of the model are replicable? 
Findings suggest the program improved students' knowledge in life sciences but did not have a significant effect on students' intent to become a scientist or affinity for science.

Interviews with project staff indicated that the key factors in the model were its conservation mission, partnerships, and the local nature of the issues involved. The primary mechanisms for sustainability and scalability beyond the five-year implementation were the digital platform, the curriculum itself, and the dissemination (with over 450 articles related to the project published in the media and academic journals). The core replicable aspects identified were the digital platform and adoption in other Keystone species contexts.

Keywords: environmental science, community partnerships, digital platform, professional development, science curriculum, out-of-school science education, environmental restoration

\section{Program Summary}

\subsection{Expected Outcomes}

CCERS activities and strategies aimed to increase STEM engagement among middle school students and STEM participation by high needs students via teachers trained in CCERS curriculum, an experience-based field science curriculum in which keystone species, the New York Harbor history, and environmentalism played key roles. As stated in Project-Based Instruction: A Review of the Literature on Effectiveness, "Research clearly indicates that project-based learning is beneficial, with positive outcomes including increases in level of student engagement, heightened interest in content, more robust development of problem-solving strategies, and greater depth of learning and transfer of skills to new situations"(Holm, 2011).

\subsection{Partnership Strategies}

The CCERS model provided a platform for student engagement in STEM through 5 pillars (see diagram below):

Pillar 1: Professional development (PD) for middle school teachers in underserved areas

Pillar 2: Student engagement with PD-trained teachers in middle school classrooms

Pillar 3: Digital platform for data management and shared learning

Pillar 4: Out-of-school mentoring for middle school student engagement

Pillar 5: Community engagement

\subsection{Target Population}

While middle school teachers in the underserved areas of New York City School District were the primary intervention targets, the targets for program impact were underserved middle school students. As stated in Cultural Studies in Science Education, underrepresented and immigrant students are often at a greater risk of losing interest in science as there is the added cultural and linguistic disconnect between school and their life experiences (Rahm, 2007).

The program team reached out to teachers, mentors, and scientists in the underserved areas of New York City Schools, and Pillar 1,3, 4, and 5 participants self-selected into the program. Teachers who underwent professional development in Pillar 1 committed to undergo training and implement part or all of the experience-based curriculum in which they had been trained, so it was their classrooms who made up Pillar 2. Most teachers followed through on at least partial commitments, and about 50\% returned for subsequent training and feedback, according to the program team. 

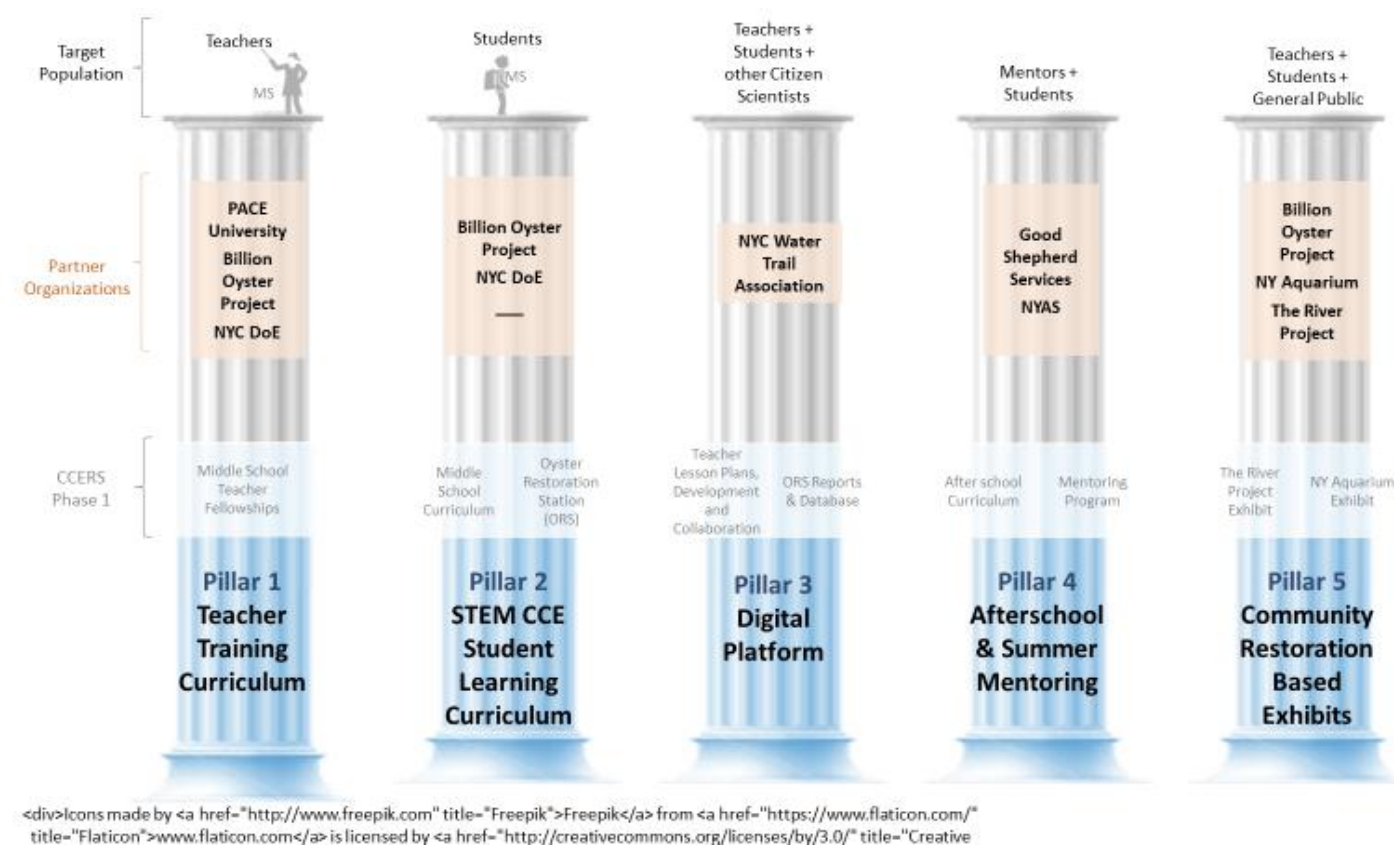

title-"Flaticon" >nww.flaticon.com</ar is licensed by <a href-"http://creativecommons.ork/licenses/by/3.0/" title-"Creative

\subsection{Community Partnerships}

CCERS partnerships made the model possible. The Billion Oyster Project (BOP) took the lead on Pillars 1-3, which formed the main part of the interventions. An essential component of any successful partnership is the need for partnership governance and leadership (Billet, Oven, Clemans \& Seddon, 2007). To create the curriculum, education professionals collaborated with teachers pioneering innovative, hands-on classroom experiences at the Harbor School on New York's Governor's Island. Pace University resources and expertise made these activities possible, as did New York's Department of Education (NYC DoE). For Pillar 3, computer science specialists through the University of Maryland (UMD) piloted the first iteration, but it was the BOP team that tailored the digital platform to meet the needs of the project's stakeholders and data sources for easier sharing and data uploading. Pillar $\mathbf{4}$ was made possible through the ongoing after-school programs via Good Shepherd Services, an organization conducting programs in New York's inner-city areas. Good Shepherd Services mentors collaborated with the New York Academy of Sciences to create an Oyster Restoration Station-centric after-school curriculum to reach more underserved students. Finally, Pillar 5 events occurred through partnerships with numerous New York-based organizations, primary among these being The River Project and the New York Aquarium. "In the Journal of Asynchronous Learning Networks, Picciano \& Steiner (2008) stated that asthe number of partnerships grows, it is becoming clear that multiple partnerships are evolving that can offer synergistic opportunities that transcend those of the individual partnerships."

\subsection{Research Participants}

A knowledge survey and an attitude survey were given to two groups of students. The treatment group of students engaged in the CCERS curriculum facilitated by teachers trained by CCERS came from 22 schools. The comparison group was made up of students who did not participate in any CCERS curriculum or activities from 15 of these schools.

Survey responses and parental consent forms were available for 493 students from the treatment group and 175 students from the comparison group. The proportion of males to females for participant and comparison groups was within one percentage point of each other. The proportion of students in each grade was also comparable, within five percentage points. Students' ages ranged from 10 to 16, with an average age of 13 years. 


\begin{tabular}{lllllllll}
\hline & \multicolumn{3}{c}{ Treatment group } & \multicolumn{3}{c}{ Comparison group } \\
Gender & $\mathrm{n}$ & $\begin{array}{l}\text { Average } \\
\text { Age(Yrs) }\end{array}$ & Min age & Max age & $\mathrm{n}$ & $\begin{array}{l}\text { Average } \\
\text { Age(Yrs) }\end{array}$ & $\begin{array}{l}\text { Min age } \\
\text { Max } \\
\text { age }\end{array}$ \\
\hline Female & $269(54 \%)$ & 12.99 & 10.60 & 15.89 & $94(54 \%)$ & 12.76 & 10.54 & 14.48 \\
\hline Male & $224(45 \%)$ & 12.85 & 10.49 & 16.45 & $79(45 \%)$ & 13.02 & 10.59 & 16.02 \\
\hline No data & $1(0.2 \%)$ & 13.26 & 13.26 & 13.26 & $2(1 \%)$ & 13.59 & 12.51 & 14.67 \\
\hline Grade: & & & & & & & & \\
\hline $6^{\text {th }}$ & $159(32 \%)$ & 11.82 & 10.49 & 14.39 & $59(34 \%)$ & 11.82 & 10.54 & 13.58 \\
\hline $7^{\text {th }}$ & $201(41 \%)$ & 13.01 & 11.93 & 14.48 & $78(45 \%)$ & 13.08 & 11.98 & 15.28 \\
\hline $8^{\text {th }}$ & $133(27 \%)$ & 14.09 & 10.89 & 16.45 & $38(21 \%)$ & 14.14 & 13.13 & 16.02 \\
\hline $10^{\text {th }}$ & $1(0.2 \%)$ & 15.51 & 15.51 & 15.51 &. &. &. &. \\
\hline
\end{tabular}

The average time between the pre and post test was 235 days $(\mathrm{SD}=11.27, \mathrm{n}=297)$ for participants and 254 days $(\mathrm{SD}=8.77, \mathrm{n}=76)$ for the comparison group.

\subsection{Interviews}

Four CCERS representatives of the Billion Oyster Project (BOP), two Good Shepherd Services leaders, two New York Academy of Sciences project partners, the project evaluator, a River Project coordinator, and the PI representing Pace University participated in the summative interviews for a total of 10 interviews with 11 project personnel in the last year of the project. Interviews were open-ended and unstructured, centering on the CCERS model and its elements. Interviewees were all centrally involved in one or more pillars of CCERS Phase 1. Nine of the interviewees were female, and two were male.

\section{Research Design (Selection, Comparison, Limitations of Data Collection)}

Initially, researchers planned to use a quasi-experimental approach to understand the program impacts, whereby comparison classrooms would be "matched" to treatment classrooms for Pillar 2 (that is, student knowledge and attitude outcomes of non-treated science teachers would be compared to that of treated science teachers). Researchers also hoped to use multi-level modeling, whereby students would be nested under teacher and school cluster variables for the purposes of understanding program effects under similar conditions. This research plan was possible in part (comparison groups were established, and most participants underwent survey assessments about knowledge and attitudes), however, due to the incomplete data about schools and teachers, researchers could not apply the initial multi-level model.

\subsection{Model Adaptation and Limitations of Data}

In addition, the realities of program implementation and partnership with NYC DoE meant that sampling was incomplete, buy-in from "comparison group" teachers was uni-centivized, "matched" classrooms could not often be found within the same school, and the realities of IRB protocols for minors meant that sample sizes were not necessarily representative. Certain student characteristics that could identify students could not be shared. As a result, the protocols associated with typical quasi-experimental design were modified to accommodate data limitations. In our final analysis, we regressed knowledge and attitude outcomes on treatment conditions, age, gender, and grade level in school in a hierarchical multivariate linear regression model. Readers should cautiously interpret the results from the model because comparison groups within Pillar 2 were subject to spillover effects since some students might have been exposed to teachers who were trained by CCERS, and samples are not necessarily representative.

Due to the partnerships specified in the planning stages of CCERS Phase 1, researchers relied on the evaluators for selection and data collection, so were unable to obtain information about some of aspects of student participation which were essential to answering Research Questions 1-2. Comparison groups for other pillars of the model proved difficult to identify and evaluate, due to issues with data collection, so identification of which components of the model affected outcomes relies on interview data. 
Like in other studies of place-based education (see Birmingham and Barton, 2014), researchers found qualitative information to be essential to understanding CCERS program impacts. Researchers conducted 10 interviews with 11 program leaders and project partners in the final year of the program. These interviews centered on key aspects of the model, challenges, and opportunities for scaling, replicating, and sustaining the model. Researchers coded the interviews in Dedoose and collaborated to define common themes relating to each question domain. Question-level codes were deductively applied, while item-level codes were inductive. Our findings from the summative round of interviews report on mechanisms for project success, sustainability, replicability, and scaling identified through coding.

\section{CCERS Project Findings}

\subsection{RQ1-2: The CCERS Model}

Research questions 1-2 ask how the model functions and which aspects are responsible for success. These questions were answerable in part by analyses of student knowledge and attitude outcomes which compared students in "treated" classrooms to those of "untreated" classrooms. Findings suggest that treatment classrooms had higher levels of knowledge in STEM topics than students in the comparison classrooms. However, in terms of attitudes toward STEM, age and grade level in school were the major contributors to the variation of the factors identified in the model.

\subsection{Project Content and Knowledge}

In looking at variation in life sciences knowledge based on test scores, we examined the role of teachers' employment of CCERS curriculum, and students' gender, age, and grade level as potential factors predicting change in knowledge between pre and post tests. The model only accounted for $4 \%$ of the variation in knowledge outcomes among students in cohorts 1-3 of the CCERS program, suggesting that unexamined factors, such as income, ethnicity, disability, and other home-related factors may have more of a role to play than those included in the model. However, students' knowledge scores in the treatment classroom were significantly higher than those in the non-treatment classroom irrespective of other factors, suggesting the program contributed to higher level of knowledge in life sciences topics.

\begin{tabular}{lllll} 
& Model 1 & Model 2 & Model 3 & Model 4 \\
Treatment & $\mathbf{7 . 9 1 * * *}$ & $\mathbf{7 . 9 4 * * *}$ & $\mathbf{7 . 9 5 * * *}$ & $\mathbf{7 . 7 4 * * *}$ \\
& $\mathbf{( - 1 . 7 5 )}$ & $\mathbf{( - 1 . 7 4 )}$ & $\mathbf{( - 1 . 7 6 )}$ & $\mathbf{( - 1 . 7 5 )}$ \\
\hline Age & & -1.29 & -1.25 & $\mathbf{- 3 . 8 0 * *}$ \\
& & $(-0.73)$ & $(-0.73)$ & $\mathbf{( - 1 . 3 0 )}$ \\
\hline Female & & 0.91 & 0.55 \\
& & & $(-1.56)$ & $(-1.56)$ \\
\hline Grade & & & $\mathbf{4 . 2 6}$ \\
& & & $\mathbf{( - 1 . 8 0 )}$ \\
\hline Intercept & $\mathbf{4 . 4 3 * *}$ & $\mathbf{2 0 . 9 7 *}$ & $\mathbf{2 0 . 0 0 *}$ & $\mathbf{2 3 . 7 9 *}$ \\
& $\mathbf{( - 1 . 4 9 )}$ & $\mathbf{( - 9 . 4 8 )}$ & $\mathbf{( - 9 . 5 6 )}$ & $\mathbf{( - 9 . 6 6 )}$ \\
\hline Adjusted R squared & 0.03 & 0.04 & 0.03 & 0.04 \\
\hline F-Statistics & 20.564 & 11.878 & 7.811 & 7.312 \\
\hline Degree of freedom & 594 & 593 & 589 & 588 \\
\hline Model p-value & $\mathbf{0 . 0 0 * * * *}$ & $\mathbf{0 . 0 0 * * * *}$ & $\mathbf{0 . 0 0 * * * *}$ & $\mathbf{0 . 0 0 * * * *}$ \\
\hline Maximum variance inflation & & 1.00 & 1.00 & 3.20 \\
factors & & & & \\
\hline Ramsey test - p-value & 1 & 0.05 & 0.02 & 0.15 \\
\hline BP test - p-value & 0.74 & 0.23 & 0.33 & 0.22 \\
\hline Cook's D & $0.01-0.04$ & $0-0.04$ & $0-0.03$ & $0-0.06$ \\
\hline Note: & & & & \\
\hline
\end{tabular}

Note: Model 1 indicates estimated effect of treatment on the differences in knowledge gains (measured in terms of percent) of the students. Model 2, 3 and 4 add student age, gender and grade one at a time. Marginal effects or 
coefficients are reported with standard errors in parentheses. Variance inflation factors $<4$ rule out the possibility of multicollinearity. Ramsey test ( $p>0.05$ ) indicates no possibility of residual non-linearity. BP test ( $p>0.05)$ rules out the possibility of heteroscedasticity of residual. Cook's D $(<1)$ rules out the possibility of outliers (reported range).

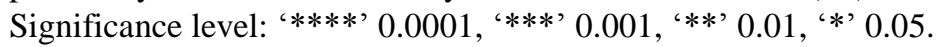

\subsection{Attitudes Toward STEM Education}

Like similar studies in prior experiential education (see Bonney et al, 2009b; Hmelo-Silver, 2004; Puttick, Cohen \& Drayton, 2015), researchers found that attitudes toward STEM careers and education, being hypothetical concepts, were both more difficult to measure quantitatively and less indicative of program success than knowledge indices. Like with the knowledge indicators, factors included in attitudinal regressions were treatment condition, age, gender, and grade level. However, CCERS treatment did not significantly affect attitudinal outcomes in any of the four models tested. The attitudinal model with the best fit accounted for $3.8 \%$ of the variation in outcomes. Younger students in the same grade had higher gains in attitudes towards science than older students in the same grade.

\begin{tabular}{|c|c|c|c|c|}
\hline & Model 1 & Model 2 & Model 3 & Model 4 \\
\hline $\begin{array}{l}\text { Treatment } \\
\text { (SE) }\end{array}$ & $\begin{array}{l}0.11 \\
(-0.07)\end{array}$ & $\begin{array}{l}0.11 \\
(-0.07)\end{array}$ & $\begin{array}{l}0.11 \\
(-0.07)\end{array}$ & $\begin{array}{l}0.10 \\
(-0.07)\end{array}$ \\
\hline Age & & $\begin{array}{l}0.06 * \\
(-0.03) \\
\end{array}$ & $\begin{array}{l}0.06 * \\
(-0.03) \\
\end{array}$ & $\begin{array}{l}-0.13^{*} \\
(-0.05)\end{array}$ \\
\hline Female & & & $\begin{array}{l}-0.07 \\
(-0.06) \\
\end{array}$ & $\begin{array}{l}-0.10 \\
(-0.06) \\
\end{array}$ \\
\hline Grade & & & & $\begin{array}{l}0.30 * * * \\
(-0.07) \\
\end{array}$ \\
\hline Intercept & $\begin{array}{l}-0.05 \\
(-0.06) \\
\end{array}$ & $\begin{array}{l}-0.80 * \\
(-0.37) \\
\end{array}$ & $\begin{array}{l}-0.76 * \\
(-0.368) \\
\end{array}$ & $\begin{array}{l}-0.47 \\
(-0.37) \\
\end{array}$ \\
\hline Adjusted R squared & 0.003 & 0.008 & 0.009 & 0.038 \\
\hline F-Statistics & 2.86 & 3.61 & 2.84 & 7.33 \\
\hline Degree of freedom & 638 & 637 & 633 & 632 \\
\hline Model p-value & 0.09 & 0.03* & $0.04 *$ & $\mathbf{0 . 0 0 * * * *}$ \\
\hline $\begin{array}{l}\text { Maximum variance } \\
\text { inflation factor }\end{array}$ & & 1.001514 & 1.00 & 3.17 \\
\hline $\begin{array}{l}\text { Ramsey test - } \\
\text { p-value }\end{array}$ & 1 & 0.16 & 0.07 & 0.03 \\
\hline BP test - p-value & 0.02 & 0.01 & 0.01 & 0.05 \\
\hline Cook's D & $0.00-0.02$ & $0.00-0.03$ & $0.00-0.03$ & $0.00-0.02$ \\
\hline
\end{tabular}

Note: Model 1 indicates estimated effect of treatment on the differences in knowledge gains (measured in terms of percent) of the students. Model 2, 3 and 4 add student age, gender, and grade one at a time. SE: Marginal effects or coefficients are reported with standard errors (SE) in parentheses. Variance inflation factors <4 rule out the possibility of multicollinearity. Ramsey test ( $>0.05$ ) indicates no possibility of residual non-linearity. BP (Breusch-Pagan) test $(p>0.05)$ rules out the possibility of heteroscedasticity of residual. Cook's D $(<1)$ rules out the possibility of outliers (reported range). Significance level: ‘***' $0.001,{ }^{\prime * *}{ }^{*} 0.01,{ }^{\prime} *$ ' 0.05 .

\subsection{Mechanisms for Model Interactions}

The regression results (and the highlighted limitations) presented above point to a) programmatic and b) research gaps that may provide insights into how students process and incorporate STEM knowledge into career intention and 
motivation. Program leaders also had a lot of experience observing the impact of the CCERS model on students. Researchers have developed the following findings about those mechanisms through the interviews, with reference to the literature on experience-based programming in K-12 education (see bibliography).

In conversations with the project team about impactful aspects of CCERS programming, the conservation mission, relevant locale, and key partnerships played the most-highlighted roles in the project's impact.

Number of mentions of key aspects of CCERS programming

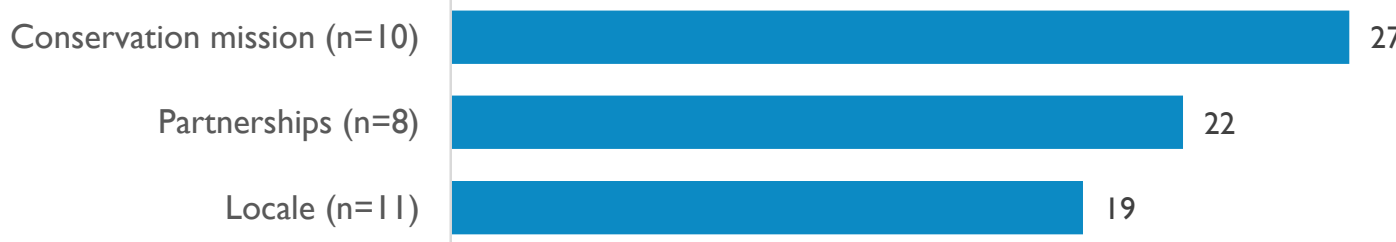

Ten of 11 interviewees highlighted the conservation mission of the program for its power to motivate student learning and engagement, not necessarily in STEM, it turns out, but in any kind of learning. Interviewees suggested that conservation may be so powerful because of the conservation topics':

- Ability to attract investment and interaction (mentioned on 11 separate occasions)

- Power to galvanize efforts and policy globally (mentioned nine separate times)

- Interdisciplinary nature (mentioned once)

- Bridging of gaps in STEM education (mentioned once)

While eight interviewees acknowledged the central role of partnerships in enabling student engagement in STEM, nearly all project leaders also highlighted the complexities inherent in collaboration and partnering. Partnerships, they said, enabled access to resources that underserved communities normally would not have, e.g. field trip capabilities and sites, community exhibits, access to the waterfront, and bureaucratic capital for mobilization. They also facilitated learning, whereby successful innovations in STEM education could be shared and transferred. School-university partnerships are beneficial because they possess the potential to facilitate change (Jones, Yonezawa, Ballesteros \& Mehan, 2002). Finally, several interviewees pointed out that the partnerships would provide the foundation for expansion of the program (see section on sustainability, below).

In terms of the New York City locale, interviewees felt that locality made conservation science a personal matter for participants in CCERS. Indeed, interviewees frequently mentioned that local advocacy was one of the most empowering parts of student engagement, whereby students began to take on the identity, not just of scientist, but of an agent of social change with the power to act, and some interviewees found this to be one of the most striking impacts of the project. Place-based environmental education can engage students in local area science experiences and allow them to become agents of community awareness and change (Lim \& Calabrese-Barton, 2006).

That oysters occupy and function to uphold New York's Harbor provides students a) opportunities to become agents of change in collective pursuits (mentioned 10 times), b) access to interactive, hands-on STEM learning in their own "backyard" (mentioned seven times), c) an alternative STEM classroom in a setting underserved students do not often explore (mentioned five times), and d) the opportunity to learn historical and social lessons alongside STEM learning (mentioned twice).

Other key aspects of the model mentioned by interviewees included: experiential/interactive learning curricula in general (15 mentions); advocacy as a part of learning (13 mentions); galvanizing science topics (11 mentions); and, integration of STEM learning with non-science concepts (nine mentions). As stated by Kearns (2014), "Field-based education transforms science learning and improves youth's sense of place, self-confidence, and motivation."

\subsection{RQ3-4: Future Suggestions}

To assess research questions three and four, we asked interviewees to a) reflect on the aspects of the program that would continue after the funding cycle, and b) reflect on the needs of the project to expand and/or replicate in other 
contexts. Responses suggested there are several key aspects of the CCERS model that are self-sustaining:

The CCER Digital Platform (Pillar 3) is open-source and has been tailored over the course of the project to accommodate the needs of the range of CCERS stakeholders. The digital platform is a data repository for oyster restoration as well as a learning hub for STEM educators in oyster restoration curriculum. Citizen, professional, academic, and student scientists currently engage with the platform and share data and New York Harbor knowledge. Moreover, the platform is open source, so the code can be copied to replicate the program for other data-sharing needs. This will require maintenance, which, for now, BOP can continue to oversee.

The BOP-CCERS Curriculum is evidence-driven, field-tested, and replicable in digital and paper formats (ideal for field visits). The curriculum relies on in-depth professional development with middle school teachers, and collaborative feedback throughout implementation in classrooms. While the curriculum is theoretically exportable, it requires expertise, investment, funding, and coordination with local departments of education to facilitate. Currently, the $6^{\text {th }}$ grade curriculum is complete, and BOP is hoping to expand coverage to all middle-school learning levels, in the short-term, and beyond.

The CCERS Symposium occurs annually in June, with no plans to discontinue after the funding cycle. This symposium brings together students of CCERS-trained teachers to present their field-based research. During the school year, teachers workshop their students' work via CCERS guidance to facilitate their students' field-based research projects. Several interviewees mentioned that many students begin to see themselves as scientists at the symposium.

Other sustainable, replicable, and/or scalable aspects of the model, according to interviewees, included: model dissemination through publications (among CCERS partners, dissemination has reached upwards of 450 published papers) and adoption in other Keystone species contexts; BOP Oyster Restoration, which will continue irrespective of CCERS; The River Project and New York Aquarium exhibits and field trip programming; future grants through federal programs; and the Good Shepherd Services/New York Academy of Sciences after-school curriculum, which is complementary to the in-school curriculum, and will be an ongoing feature of their programming (see chart below for rate of interview mentions).

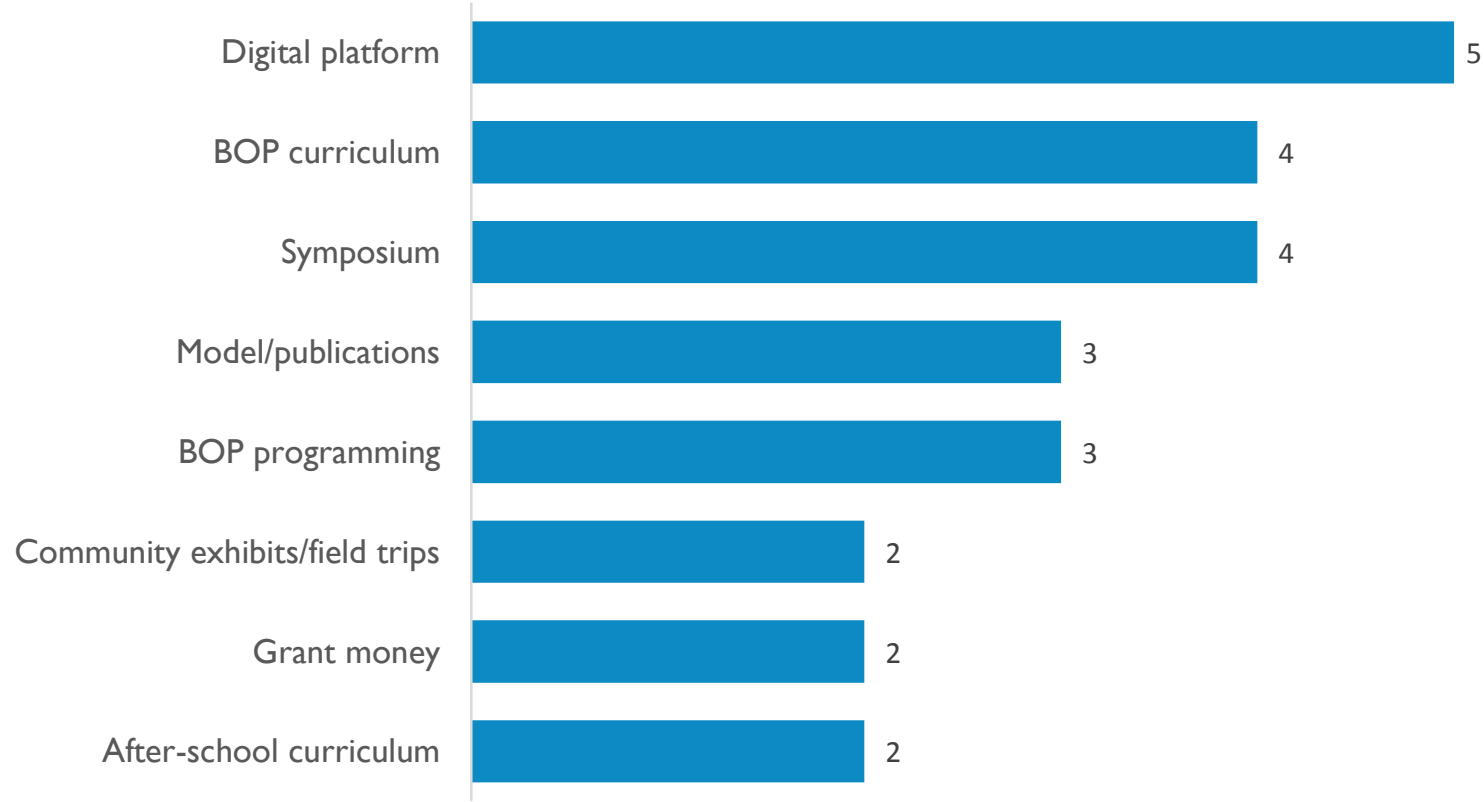

For CCERS strides in STEM education to be maintained, however, interviewees mentioned several conditions of sustainability. Most respondents agreed that with public schools being overcrowded and teachers being under-funded, compensation for teachers' time spent in professional development is necessary. The importance of logistics was another recurring theme during interviews, as field visits necessarily entail permissions granted through DoE, transportation, signed permission slips, completed evaluations, and other coordination challenges among partners. The 
digital platform needs ongoing maintenance to retain its status at the forefront of citizen science data-sharing. To replicate the curriculum requires constant marketing and dissemination, which is time-consuming. Partnerships also require a great deal of investment. The curriculum could use a graphic designer to accommodate formatting and comprehension needs. Teachers undergoing professional development need a central location in which to learn and workshop.

Evaluation and research are ongoing, and interviews indicated data collection among so many partners is difficult to coordinate. Like with CCERS programming, DoE liaisons will need strengthening to support research and evaluation needs. The data collection protocols were among the most-cited challenges of participation in the program, and coverage was incomplete. Buy-in for comparison groups was difficult to manage, which could result in few, none, or contaminated comparison groups.

\section{Research Discussion}

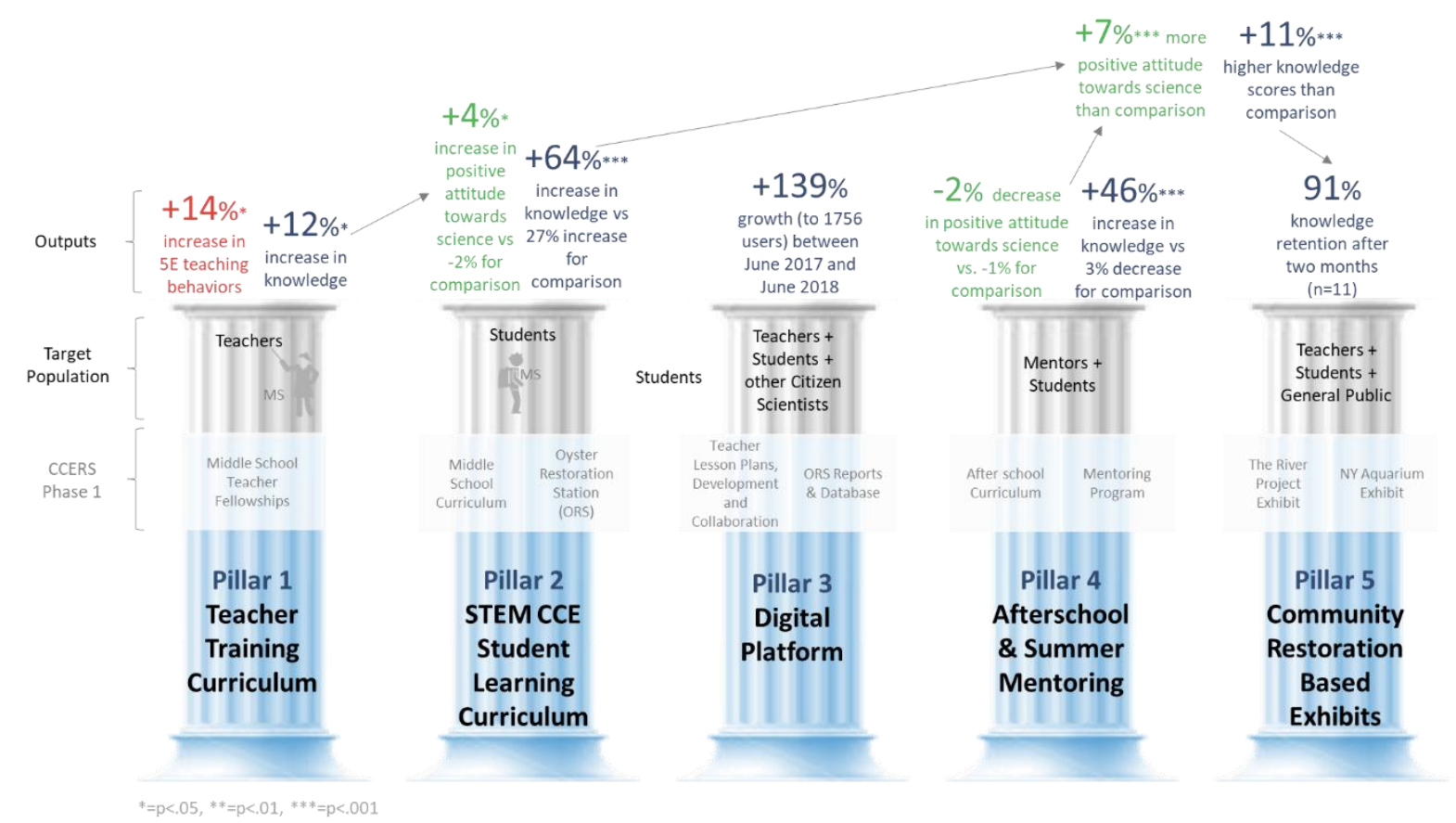

The interviewees' assessments of CCERS impacts on STEM engagement highlight the situated nature of all learning, where personal, social, and historical contexts shape individuals' interactions with science (see Falk \& Storksdjeck, 2005). Orion \& Hofstein (1994) suggest that the preconditions for science learning in experiential settings include not only science knowledge/skill levels, but also local acquaintance and prior preparation for the off-site visit. Endreny (2010) found that learning in these contexts goes way beyond STEM and touches on other topics and aspects of young students' lives.

Perhaps the interactivity that experiential science learning engenders provides some context for Bonney et al.'s (2009a) findings (and ours) that such experiences do not directly impact attitudes toward STEM. That is, if students are busily engaging the world around them, synthesizing concepts, collaborating to solve problems, and developing a sense of social responsibility, then STEM interest is just one arena among many in which students may be experiencing change. For instance, if a student encounters water pollution that threatens life in New York City's Harbor, she may not necessarily be identifying as a future scientist so much as an energy activist, even though her newfound identity may lead her into STEM fields in the future. More important, she has seen herself as capable of enacting change and better comprehending the world around her. Sobel's (2005) states that through connections to community and nature, students develop stronger ties to their community enhances students' appreciation for the natural world and creates a heightened commitment to serving as active, contributing citizens. 
The findings from Phase 1 revealed some weaknesses in the measures of engagement in STEM used. Due to the complex and embedded nature of K-12 engagements in science education, these measures will require revision to meet the needs identified in the literature and throughout the project (see below). Future researchers may adapt to accommodate the needs of time-pressed instructors by finding ways to use easily collected tracking, institutional, and web use data to measure program impacts. A dosage model may compensate for the difficulty of procuring comparison groups, for instance.

The project team for CCERS was composed of education activists whose love of science had been ignited in both formal and informal education settings. This paved the way for a highly collaborative, replicable, and engaging program.To scale the program, the next frontier is the policy arena, in which advocacy and science can team up for conservation for true impact. Another focus of the program in Phase 2 is computer science, to facilitate the sharing, processing, and analysis of high-quality data.

\section{References}

Birmingham, D., \& Calabrese Barton, A. (2014). Putting on a green carnival: Youth taking educated action on socioscientific issues. J Res Sci Teach, 51, 286-314. https://doi.org/10.1002/tea.21127

Bonney, R., Ballard, H., Jordan, R., McCallie, E., Phillips, T., Shirk, J., \& Wilderman, C. C. (2009b). Public participation in scientific research: Defining the field and assessing its potential for informal science education. A CAISE Inquiry Group Report. Washington, D.C.: Center for Advancement of Informal Science Education (CAISE).

Bonney, R., Cooper. C. B., Dickinson, J., Kelling, S., Phillips, T., Rosenberg, K. V., \& Shirk, J. (2009a). Citizen science: A developing tool for expanding science knowledge and scientific literacy. BioScience, 59(11), 977-984. https://doi.org/10.1525/bio.2009.59.11.9

Endreny, A. H. (2010). Urban 5th graders conceptions during a place-based inquiry unit on watersheds. J. Res. Sci. Teach, 47, 501-517. https://doi.org/10.1002/tea.20348

Falk, J., \& Storksdieck, M. (2005). Using the contextual model of learning to understand visitor learning from a science center exhibition. Sci. Ed., 89, 744-778. https://doi.org/10.1002/sce.20078

Hmelo-Silver, C.E. (2004). Problem-based learning: What and how do students learn. Educational Psychology Review 16(3), 235-266.

Holm, M. (2011). Project-Based Instruction: A Review of the Literature on Effectiveness in Prekindergarten through $12^{\text {th }}$ Grade Classrooms. Rivier Academic Journal, 2(7).

Kearns, Jack J. (2014). Using Environmental Science Education to Empower Urban Youth to Overcome Environmental Injustices and Become Engaged Eco-Citizens. Master's Projects, Paper 28.

Lim, M., \& Calabrese Barton, A. (2006). Science learning and a sense of place in an urban middle school. Cultural Studies of Science Education, 1, 107-142.

M. Jones, S. Yonezawa, E. Ballesteros, H., \& Mehan, L. (2002). Shaping pathways to higher education. Educational Researcher, 31(2), 3-11.

Melaville, A., Berg, A. C., \& Blank, M. J. (2006). Community-Based Learning: Engaging Students for Success and Citizenship.Partnerships/Community. $40 . \quad$ Retrieved from https://digitalcommons.unomaha.edu/slcepartnerships/40

Orion, N., \& Hofstein, A. (1994). Factors that influence learning during a scientific field trip in a natural environment. J. Res. Sci. Teach, 31, 1097-1119. https://doi.org/10.1002/tea.3660311005

Picciano, A.G., \& Steiner, R.V. (2008). Bringing the real world of science to children: A partnershipof the American Museum of Natural History and the city University of New York. Journal of Asynchronous Learning Networks, 12(1).

Puttick, G., Cohen, E.D., \& Drayton, B. (2015). A Study of the Literature on Lab-Based Instruction in Biology. The American Biology Teacher, 77(1), 12-18. https://doi.org/10.1525/abt.2015.77.1.3

Rahm, J. (2008). Urban youths' hybrid positioning in science practice at the margin: A look inside a school-museum-scientist partnership project and an after school science program. Cultural Studies of Science Education, 3, 97-121. 
Rand Corporation. (2016). Summer Learning programs can benefit low-income students, study finds. Science Daily, September 7. Retrieved from https://www.sciencedaily.com/releases/2016/09/160907125115.htm

Sobel, D. (2005). Place-based education: Connecting classrooms and communities. Great Barrington, MA: The Orion Society.

Stephen Billett, S., Ovens, C., Clemans, A., \& Seddon, T. (2007). Collaborative working and contested practices: forming, developing and sustaining social partnerships in education. Journal of Education Policy, 22(6), 637-656. https://doi.org/10.1080/02680930701625288

\section{Note}

Note 1. The 5 E's, Enhancing Education, http://enhancinged.wgbh.org/research/eeee.html 